\title{
Cardiorespiratory Monitoring during Neonatal Resuscitation for Direct Feedback and Audit
}

\author{
Jeroen J. van Vonderen ${ }^{1 \star}$, Henriëtte A. van Zanten ${ }^{1}$, Kim Schilleman ${ }^{1}$, Stuart B. Hooper, \\ Marcus J. Kitchen ${ }^{4}$, Ruben S. G. M. Witlox ${ }^{1}$ and Arjan B. te Pas ${ }^{1 *}$ \\ 'Division of Neonatology, Department of Pediatrics, Leiden University Medical Center, Leiden, Netherlands, ${ }^{2}$ Ritchie Centre, \\ Hudson Institute of Medical Research, Melbourne, VIC, Australia, ${ }^{3}$ Department of Obstetrics and Gynaecology, Monash \\ University, Melbourne, VIC, Australia, ${ }^{4}$ School of Physics and Astronomy, Monash University, Melbourne, VIC, Australia
}

Neonatal resuscitation is one of the most frequently performed procedures, and it is often successful if the ventilation applied is adequate. Over the last decade, interest in seeking objectivity in evaluating the infant's condition at birth or the adequacy and effect of the interventions applied has markedly increased. Clinical parameters such as heart rate, color, and chest excursions are difficult to interpret and can be very subjective and subtle. The use of ECG, pulse oximetry, capnography, and respiratory function monitoring can add objectivity to the clinical assessment. These physiological parameters, with or without the combination of video recordings, can not only be used directly to guide care but also be used later for audit and teaching purposes. Further studies are needed to investigate whether this will improve the quality of delivery room management. In this narrative review, we will give an update of the current developments in monitoring neonatal resuscitation.

Keywords: resuscitation, neonate, respiratory function monitor, pulse oximetry, video, ECG

\section{INTRODUCTION}

During neonatal transition, lung aeration is pivotal for changes in respiratory and cardiovascular function required for survival $(1,2)$. However, of the 130-136 million infants born annually in the world, approximately $3-5 \%$ of term infants and $60 \%$ of preterm infants fail to aerate their lungs spontaneously and require some form of resuscitation $(3,4)$. In most cases, neonatal "resuscitation" comprises only the establishment of adequate ventilation $(5,6)$, which reflects the importance and vulnerability of infants as they transition to pulmonary gas exchange. Both experimental and clinical studies have demonstrated that even short periods of inappropriate respiratory support can have severe consequences, leading to lung and brain injury, especially in preterm infants (7-9). This injury, which takes place in the first minutes of life, can have a major impact on some of the important morbidities associated with prematurity, such as bronchopulmonary dysplasia and intraventricular/ periventricular hemorrhage $(10,11)$.

The effect of respiratory support should be evaluated and closely monitored in order to stay within the known safe ranges (12). Traditionally, the infant's condition and effectiveness of resuscitation was evaluated by judging color, chest excursions, and by palpation or auscultation of the infant's heart rate (HR) (13). But evaluating color, manually counting heart beats, and visualizing chest excursions are inherently inaccurate (14-16), leading to the recommendation that pulse oximetry (PO) or ECG should be used $(3,17)$. Although experts recommend the use of respiratory function monitoring (RFM) (18), this is not mandated by the international resuscitation guidelines, and in 
most neonatal units, ventilation is still evaluated by chest excursions (19). However, real-time quantitative information could improve mask technique and ventilation (12).

While regular auditing has been employed to improve quality of the interventions performed by caregivers, this is difficult in delivery room management as few objective parameters can be used and these are usually not recorded. The resuscitation chart is often documented retrospectively, and eyewitness testimonies of stressful events are often inaccurate $(20,21)$. As a result, high quality documentation can be difficult to obtain and preprinted resuscitation pages in the medical records usually ask for few details. Recording of physiological parameters and video images during neonatal resuscitation could improve quality as auditing is possible and assists in documentation, as it provides detailed information on resuscitation.

In this review, we will describe the current knowledge in monitoring neonatal resuscitation for direct feedback to guide the resuscitator with ongoing care and for feedback later, when it is used for auditing.

\section{WHY MONITOR?}

Lung aeration is the key factor that initiates pulmonary and hemodynamic changes at birth, which emphasizes the significance of adequate respiratory support/ventilation as the cornerstone of resuscitation/stabilization when transition fails. Management of infant care in the first minutes after birth can severely impact morbidities associated with prematurity, resulting in major adverse outcomes (7-9). Although most clinical trials in delivery room management have failed to show a decrease in morbidity and mortality, there is much experimental data demonstrating that respiratory support given at birth can injure the preterm infant, with potentially life long consequences (7). In addition, large clinical studies in very preterm infants reported higher mortality rates and an increased risk of lung and brain injury with increasing levels of delivery room resuscitation (22-24).

At birth, the lungs of very preterm infants are uniquely susceptible to injury because they are structurally immature, surfactantdeficient, liquid-filled, and not supported by a stiff chest wall (25). Gas volume and lung compliance of newborns greatly changes over the first few breaths as airway liquid is replaced with air. This highlights the large differences in regional lung mechanics that occur when the lung only partially aerates (26). Spontaneously breathing infants develop high transthoracic pressures over the first few breaths, and relatively high positive pressures are required to initiate ventilation (27). However, compliance rapidly increases as more of the lung aerates resulting in lower pressure requirements to achieve a functional tidal volume $\left(\mathrm{V}_{\mathrm{T}}\right)$ with subsequent breaths. In addition, although the lung, heart, and brain are often considered independently, they are intimately linked, particularly at birth. Treatments aimed to provide respiratory support can have severe adverse consequences for the preterm heart and brain (7). For example, positive pressure ventilation (PPV) can not only cause lung injury but can also adversely affect the systemic circulation and cerebral circulation. Similarly, inflammation resulting from lung injury can induce a systemic inflammatory response that includes the brain (7).
Hyperoxia can lead to oxidative stress and tissue injury (28, 29). Excessive oxygen exposure should be avoided during stabilization at birth. Recently, updated international resuscitation guidelines recommend that respiratory support in term infants should start with air (29-31). Less clinical data are available for preterm infants, although even a short period of hyperoxia in preterm infants at birth increases oxidative stress and inflammation, and preterm infants initially exposed to a high $\mathrm{FiO}_{2}$ have an increased risk for bronchopulmonary dysplasia (32). These findings suggest that in the first minutes after birth, avoiding the use of high oxygen concentrations may reduce acute lung injury, particularly in very preterm infants.

On the other hand, hypoxia is known to inhibit breathing in the fetus due to a direct inhibitory input on the respiratory center of the brain (33). Although a temporal change in $\mathrm{O}_{2}$ sensitivity occurs in days/weeks after birth (34) and most preterm infants breathe at birth $(35,36)$, it is not known when the switch from respiratory suppression to stimulation occurs in response to hypoxia. It is possible that hypoxia immediately after birth will cause a weakened or absent respiratory drive, particularly in preterm infants, who are essentially exteriorized fetuses. Indeed, maturation of the hypoxic sensitivity for breathing is delayed in preterm lambs (34).

In addition, the success of ventilation strategies to support respiratory function at birth in the newborn is largely dependent on the technique and strategy applied. The initial approach is to use non-invasive ventilation applied using a facemask, but most caregivers are not aware or adequately informed concerning effectivity of their mask technique (36).

For the aforementioned reasons, it seems obvious that close monitoring of physiological parameters is necessary to provide adequate respiratory support and keep monitored values in the defined "safe" ranges.

\section{DIRECT FEEDBACK}

\section{Pulse Oximetry}

When measured by auscultation or by palpation of the umbilical cord, HR is commonly underestimated at birth, possibly because insufficient time is taken to accurately count beats (37). Indeed, studies have observed that caregivers spend only on average $6 \mathrm{~s}$ to count $(38,39)$, which is probably due to the time limits mandated by resuscitation guidelines (19). PO has been recommended for monitoring and evaluating the infant's condition, and the effect of interventions on infants at birth has replaced assessment of skin color and auscultating HR for evaluation (3). Different PO devices are available; however, no significant differences in HR measurements have been found (40).

Nomograms based on PO measurements have been developed to guide the caregiver during neonatal resuscitation providing acceptable reference ranges $(41,42)$. PO measurements obtained for nomograms are derived from infants where the umbilical cord was clamped immediately (41). Delayed cord clamping and milking $(43,44)$ leads to higher $\mathrm{SpO}_{2}$ values and lower $\mathrm{HR}$, especially in the first minutes after birth. As delayed cord clamping is now recommended for term infants (19) and implemented 
in most hospitals worldwide, caregivers should reconsider which nomograms to use. When using the international accepted nomograms, caution should be taken in what we define "healthy" normal transition and which values we find acceptable.

Another concern is that for development of PO nomograms, only good quality data points were used $(37,41)$. Low quality data [low signal identification and quality $($ SIQ $<0.3)$ ] and data with low perfusion indices were excluded retrospectively, which comprised $50 \%$ of collected data $(37,41)$. It is obvious that this does not reflect the real situation when clinicians need to evaluate the infant directly after birth and must deal with both high and low quality data. $\mathrm{SpO}_{2}$ measurements with low signal quality proved to be reliable for monitoring the infant's condition, but HR could be underestimated (45).

\section{ECG}

ECG is considered as gold standard for measuring HR, and recent guidelines recommend ECG use, when available, to monitor HR at birth (19). Studies have shown feasibility of collecting ECG data at birth and a reliable signal were obtained faster when compared to PO $(17,46)$. While HR measurements collected simultaneously by PO and ECG have led to the conclusion that HR measured by PO is accurate (37), a temporal analysis of similar data has shown that PO underestimates HR in the first minutes after birth (17). Difference in HR measured by PO and ECG are mostly likely due to large hemodynamic changes that occur during transition. In the first minutes after birth, especially after immediate cord clamping, cardiac output will be decreased temporarily, which could decrease systolic blood flow pulses that are not detected by PO (17, 47). It is also possible that the direct reversal of the ductal shunt, which occurs directly after birth, diminishes pulse waves peripherally $(17,47)$. We recommend the use of ECG, when in doubt and when available. However, sensor application can be hampered by body fluids on the skin and care must be taken not to damage the skin. Accuracy of Doppler devices is promising compared to ECG (48). In the future, these devices could be used to determine nomograms instead of relying on nomograms drafted with PO.

\section{Near Infrared Spectroscopy}

The brain is the most important organ of the human body. Monitoring of the neonatal brain could provide additional information during immediate transition and may help to guide resuscitation. Near infrared spectroscopy (NIRS) is the most promising method, since it provides continuous data monitoring and is feasible even in VLBW infants receiving resuscitation interventions (49). Reference values are available for term and preterm infants during transition $(50,51)$.

\section{Respiratory Function Monitoring}

The use of RFM during resuscitation at birth is currently not recommended in the international guidelines, as there is no evidence that it improves outcome (19). Despite a few trials that are currently running, RFMs are not routinely used in the delivery room to assess adequate neonatal transition and ventilation. Nevertheless, we believe that there are several reasons why the use of a RFM at birth could be helpful during neonatal resuscitation by removing subjectivity involved in evaluating resuscitation
(16). Spontaneous breathing is often missed or misjudged, and for this reason, unnecessary ventilation can be given $(36,38)$. Studies have shown that inflation pressures during ventilation at birth are a poor proxy for actual volumes delivered $(36,52)$. During transition at birth, pulmonary dynamics change quickly, and with a similar inflation pressure, very different $\mathrm{V}_{\mathrm{T}} \mathrm{s}$ can be achieved initially compared with later, during subsequent ventilation. Often inadequate and injuriously high $\mathrm{V}_{\mathrm{T}}$ s occurred during resuscitation $(18,36)$. Also mask ventilation is often hampered by large mask leak and obstruction $(36,52-56)$, which was often not noticed by caregivers $(36,52-56)$.

In a small feasibility study, preterm infants were mask ventilated at birth and randomized as to whether a RFM was visible or not. In the RFM visible group, the mask was more frequently repositioned, and there was a significant decrease in mask leak and intubation as compared to the group where the RFM was not visible (57). Alternatively, combining all physiological parameters $\left[\mathrm{V}_{\mathrm{T}} \mathrm{S}\right.$, pressures, fractional oxygen given $\left.\left(\mathrm{FiO}_{2}\right)\right]$ with $\mathrm{SpO}_{2}$ and HR onto one screen could increase the chance that caregivers observe the added RFM parameters.

When defining the target range of $\mathrm{V}_{\mathrm{T}} \mathrm{S}$ for infants at birth, the following considerations have to be taken into account. The ratio between functional residual capacity (FRC), which is $11 \mathrm{~mL} / \mathrm{kg}$, and total lung capacity $(19 \mathrm{~mL} / \mathrm{kg})$ is smaller in preterm than in term infants $(58,59)$. Experimental studies have shown that $\mathrm{V}_{\mathrm{T}} \mathrm{S}>8 \mathrm{~mL} / \mathrm{kg}$ distend the lung above total lung capacity and cause lung injury $(60,61)$. Only five rapid inflations with large $V_{T} S$ at birth can cause lung injury (62) and abolish benefits conferred with surfactant treatment (63). Although it is known that overinflation causes lung injury (64), high inflation rates causing large shear stress are also injurious (65). Many infants can receive inappropriate $\mathrm{V}_{\mathrm{TS}}$ within minutes of birth (12). Indeed, $\mathrm{V}_{\mathrm{T}} \mathrm{S}$ ranged from 0 to $>30 \mathrm{~mL} / \mathrm{kg}$ during resuscitation with a T-piece, with the majority $(85 \%)$ of preterm infants receiving excessively high $\mathrm{V}_{\mathrm{T}} \mathrm{s}(>8 \mathrm{~mL} / \mathrm{kg})(66)$.

During mask ventilation, the complete respiratory tract (nasopharynx, trachea, and lungs) is pressurized and ventilated. During inflations, there is volume displacement of the nasopharynx, which does not occur during spontaneous breathing (67). This could even lead to $\mathrm{V}_{\mathrm{T}}$ measurements during ventilation against a closed larynx (Figure 1). During fetal development, laryngeal adduction maintains a higher intra-pulmonary pressure, essential for lung development $(68,69)$. It is likely that the larynx remains mostly closed at birth, only opened briefly during a breath, which prevents face mask ventilation from inflating the lung $(2,70,71)$.

Several studies have shown that spontaneously breathing preterm infants supported only by CPAP, have a mean $\mathrm{V}_{\mathrm{T}}$ of $4.4 \mathrm{~mL} /$ $\mathrm{kg}(36,52,72)$. Until more data are provided concerning the "safe range," it seems prudent to use $4-8 \mathrm{~mL} / \mathrm{kg}$ (12). However, it is likely larger $\mathrm{V}_{\mathrm{T}} \mathrm{S}$ are initially needed when lung liquid clearance, lung aeration, and FRC needs to be established compared to the subsequent ventilation when the lungs are aerated and FRC has to be maintained.

\section{Exhaled $\mathrm{CO}_{2}$}

Exhaled $\mathrm{CO}_{2}$ can be added to monitor lung function at birth. Experimental studies and clinical observations in intubated 


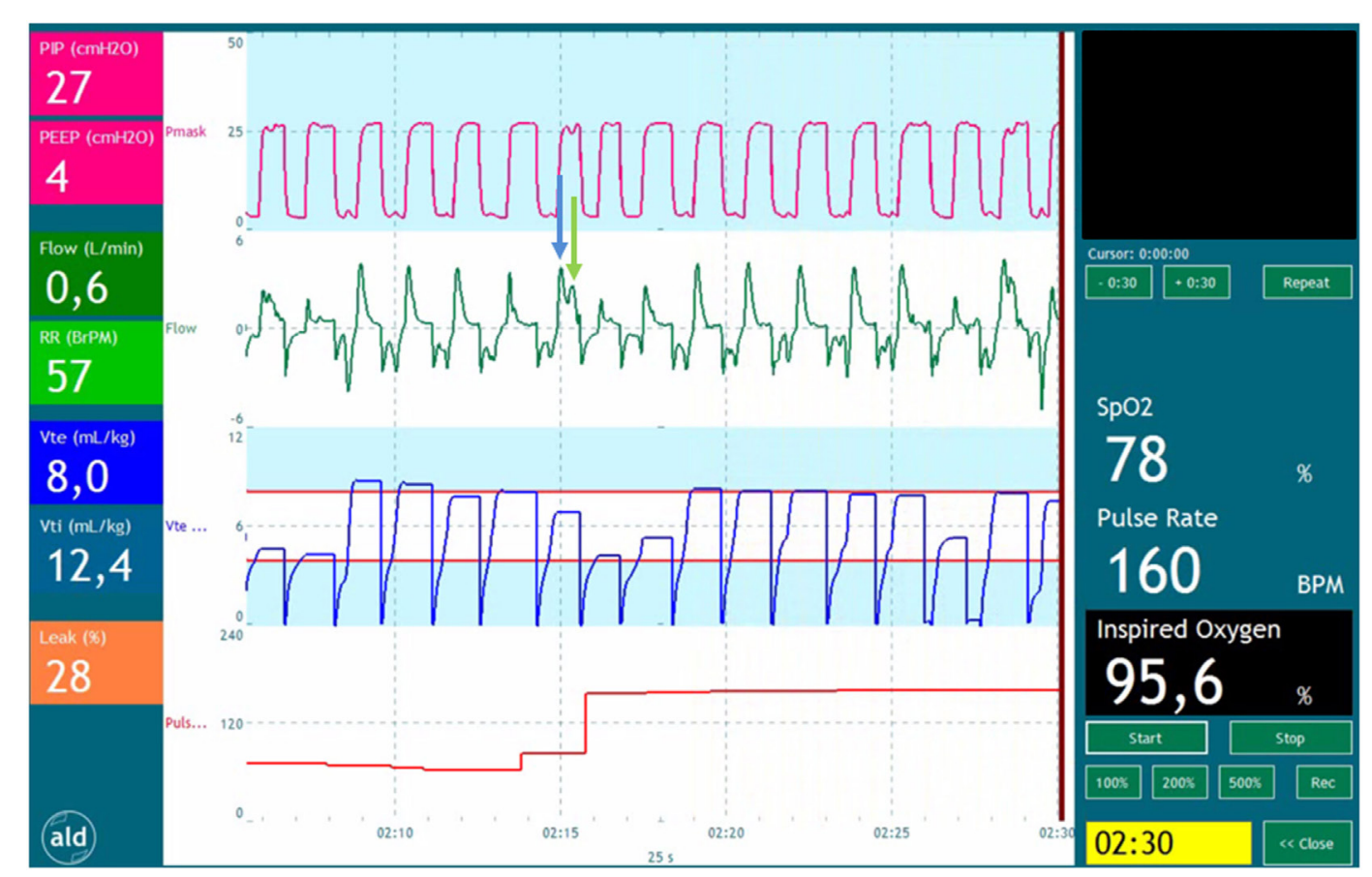

FIGURE 1 | Recording of a preterm infant receiving positive pressure ventilation. The tracing shows pressure (red), flow (green), expiratory volume (blue), and pulse rate (red). The blue arrow points a part of the volume entering the oropharynx at the start of the inflation. The green arrow points at the part of volume entering the lungs when the pressure time integral is large enough to overcome the resistance of the glottis and upper airway.

infants have shown that end-tidal $\mathrm{CO}_{2}$ measurements correlated well with $\mathrm{V}_{\mathrm{T}} \mathrm{s}$ delivered and amount of lung recruitment (73). Endtidal $\mathrm{CO}_{2}$ measurements are taken during the "plateau phase" of each expiration, and this can be influenced greatly when this plateau phase is not reached due to leak. Volumetric measurements, which integrate $\mathrm{CO}_{2}$ signal, for the whole inspiration are much more reliable (NM3, Respironics, Eindhoven, the Netherlands).

It was recently showed that spontaneous breathing, added dead space (mask, flow and $\mathrm{CO}_{2}$ sensors), mask leak, and laryngeal obstruction during mask ventilation greatly influences exhaled $\mathrm{CO}_{2}$ measurements and can easily misinform the caregiver (Figure 2) (74).

Ideally exhaled $\mathrm{CO}_{2}$ therefore should be combined with tidal volume measurements to identify adequate ventilation, provided that added dead space is acceptable.

\section{LATE FEEDBACK}

Auditing clinical interventions is necessary for quality assurance and should be an integral part of the daily health care. Neonatal resuscitation is commonly audited by using the resuscitation charts documented by the caregiver.

Videotaping emergency medical procedures first emerged in the 1960s (75) and was pioneered in neonatal resuscitation by Finer $(76,77)$. Videotaping of DR management has shown that $54 \%$ of caregivers deviated from the guidelines, most frequently in respiratory management (77). Several items were scored during review of videos, and several deficiencies were frequently

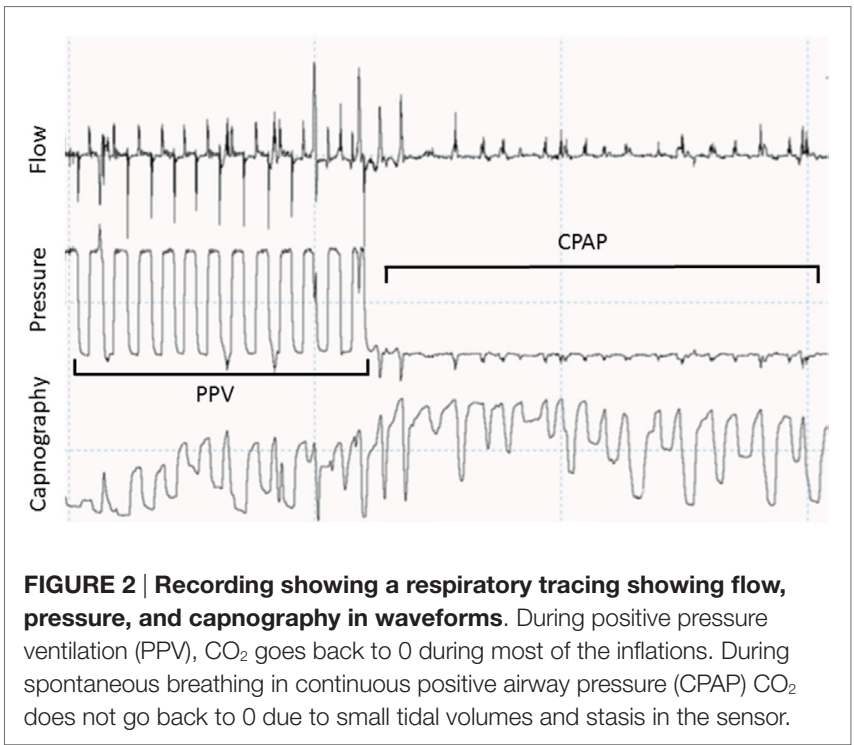

detected such as improper detection of chest excursions, suction technique, bag and mask technique, and oxygen use. However, although chest excursions were evaluated by a different caregiver on the video, this remains a subjective measurement for applying adequate ventilation. Regular audits of neonatal resuscitation have been implemented in our unit (Leiden University Medical Centre, the Netherlands), and recording of physiological parameters 
$\left(\mathrm{SpO}_{2}, \mathrm{HR}, \mathrm{FiO}_{2}\right.$, air flow, pressures, volume and mask leak) were added to the video. During these audits, we observed that caregivers deviated even more often (80\%) from the guidelines (7). These deviations most often occurred in the respiratory management (71\%; choice of respiratory support, frequency and duration of initial inflations and pressures given) and heat prevention (37\% of occasions) (38). This was in agreement with observations in a low-resource setting (78). An important observation was that evaluation of respiratory support and the MRSOPA (mask reposition, suctioning, open airway, increase pressure and consider alternative airway) was frequently not performed. In addition, resuscitation charts often appeared inaccurate or incorrect compared with the recordings (20). Recordings are reviewed plenary with all staff available, on a weekly bases. During this meeting, the intervention is discussed by an independent reviewer after which everyone is invited to give feedback.

\section{Ethical and Legal Aspects}

Recording physiological data and especially video recording are subject to strict legislation concerning privacy. Data collection for audit, however, is subject to less strict rules, as it is intended to improve health care and is a tool for quality assurance. Therefore, it is an integral part of health-care delivery (79). In the United States, the use of video's without asking written consent is protected by law (80). In Australia and the Netherlands, protocols were assessed by the medical ethical committee, but parental consent was deemed unnecessary $(36,77,81,82)$.

Recording the performance of caregivers during resuscitation can cause concern among staff members. The events of resuscitation could be subject of a disciplinary investigation. This can raise questions with clinicians concerning their anonymity. But de-identification of data could prevent the use for data for legal purposes. Parents very infrequently refuse the use of recordings for audit as well as for research purposes (82). Also, in our experience parents find it acceptable that recordings are made during resuscitation.

\section{Which RFM to Use?}

Although mostly used for research there are different types of RFMs available. The three commercially available monitors use

\section{REFERENCES}

1. Hooper SB, Siew ML, Kitchen MJ, Te Pas AB. Establishing functional residual capacity in the non-breathing infant. Semin Fetal Neonatal Med (2013) 18:336-43. doi:10.1016/j.siny.2013.08.011

2. Siew ML, Wallace MJ, Kitchen MJ, Lewis RA, Fouras A, Te Pas AB, et al. Inspiration regulates the rate and temporal pattern of lung liquid clearance and lung aeration at birth. J Appl Physiol (2009) 106:1888-95. doi:10.1152/ japplphysiol.91526.2008

3. Wyckoff MH, Aziz K, Escobedo MB, Kapadia VS, Kattwinkel J, Perlman JM, et al. Part 13: neonatal resuscitation: 2015 American Heart Association guidelines for cardiopulmonary resuscitation and emergency cardiovascular care. Circulation (2015) 132:S543-60. doi:10.1161/CIR.0000000000000267

4. Vento M, Saugstad OD. Resuscitation of the term and preterm infant. Semin Fetal Neonatal Med (2010) 15:216-22. doi:10.1016/j.siny.2010.03.008

5. Perlman JM, Risser R. Cardiopulmonary resuscitation in the delivery room. Associated clinical events. Arch Pediatr Adolesc Med (1995) 149:20-5. doi:10.1001/archpedi.1995.02170130022005 different techniques to measure gas flow and software for calculations of the tidal volume. The most commonly used device in the delivery room is the Florian Neonatal RFM (Acutronic Medical Systems AG, Hirzel, Switzerland) using a hotwire anemometer (11, 13-15), but studies have also been performed with a Respironics Novametrix Non-Invasive Cardiac Output (NICO) monitor (Novametrix Medical Systems Inc., Wallingford, Connecticut), using a differential pressure pneumotachometers with a fixed orifice $(11,12)$. In the Monitor trial (NTR 4104), a newly developed resuscitation monitor is used with a built-in New Life Box Neo-RSD (NLB Neo-RSD, Advanced Life Diagnostics UG, Weener, Germany) for lung function measurements, using a differential pressure pneumotachometers with a fixed orifice. Also a low cost monitor has been developed (Laerdal Newborn Resuscitation Monitor, Laerdal, Stavanger, Norway) using a hot wire anemometer and is recently used in studies in a low-resource setting (83).

\section{CONCLUSION}

Although perinatal caregivers are trained for neonatal resuscitation, it remains a stressful event. Inadvertently, potential injurious interventions can be given by the caregiver during the infant's most vulnerable moment when it is undergoing a major physiological transformation, especially in preterm infants. Traditional parameters on which the infant's condition and the effectiveness of interventions are assessed have shown to be subjective and inaccurate. Monitoring physiological parameters is feasible, easy to do, and gives an objective feedback directly during resuscitation or later when it is used for audit. This feedback will improve performance of caregivers during neonatal resuscitation, but further studies are needed to determine whether this will improve patient outcomes.

\section{AUTHOR CONTRIBUTIONS}

JV and AP wrote the first draft of the manuscript, critically reviewed the manuscript, and approved the final version. HZ, $\mathrm{KS}, \mathrm{SH}, \mathrm{MK}$, and RW critically reviewed the manuscript and approved the final version.

6. Te Pas AB, Lopriore E, Engbers MJ, Walther FJ. Early respiratory management of respiratory distress syndrome in very preterm infants and bronchopulmonary dysplasia: a case-control study. PLoS One (2007) 2:e192. doi:10.1371/ journal.pone.0000192

7. Polglase GR, Miller SL, Barton SK, Baburamani AA, Wong FY, Aridas JD, et al. Initiation of resuscitation with high tidal volumes causes cerebral hemodynamic disturbance, brain inflammation and injury in preterm lambs. PLoS One (2012) 7:e39535. doi:10.1371/journal. pone.0039535

8. Polglase GR, Miller SL, Barton SK, Kluckow M, Gill AW, Hooper SB, et al. Respiratory support for premature neonates in the delivery room: effects on cardiovascular function and the development of brain injury. Pediatr Res (2014) 75:682-8. doi:10.1038/pr.2014.40

9. Te Pas AB, Walther FJ. A randomized, controlled trial of delivery-room respiratory management in very preterm infants. Pediatrics (2007) 120:322-9. doi:10.1542/peds.2007-0114

10. Soraisham AS, Lodha AK, Singhal N, Aziz K, Yang J, Lee SK, et al. Neonatal outcomes following extensive cardiopulmonary resuscitation in the delivery 
room for infants born at less than 33 weeks gestational age. Resuscitation (2014) 85:238-43. doi:10.1016/j.resuscitation.2013.10.016

11. Wyckoff MH, Salhab WA, Heyne RJ, Kendrick DE, Stoll BJ, Laptook AR. Outcome of extremely low birth weight infants who received delivery room cardiopulmonary resuscitation. J Pediatr (2012) 160:239-44. doi:10.1016/j. jpeds.2011.07.041

12. Schmolzer GM, Te Pas AB, Davis PG, Morley CJ. Reducing lung injury during neonatal resuscitation of preterm infants. J Pediatr (2008) 153:741-5. doi:10.1016/j.jpeds.2008.08.016

13. International Liaison Committee on Resuscitation. The International Liaison Committee on Resuscitation (ILCOR) consensus on science with treatment recommendations for pediatric and neonatal patients: neonatal resuscitation. Pediatrics (2006) 117:e978-88. doi:10.1542/peds.2006-0350

14. Kamlin CO, O'Donnell CP, Everest NJ, Davis PG, Morley CJ. Accuracy of clinical assessment of infant heart rate in the delivery room. Resuscitation (2006) 71:319-21. doi:10.1016/j.resuscitation.2006.04.015

15. O’Donnell CP, Kamlin CO, Davis PG, Carlin JB, Morley CJ. Clinical assessment of infant colour at delivery. Arch Dis Child Fetal Neonatal Ed (2007) 92:F465-7. doi:10.1136/adc.2007.120634

16. Brugada M, Schilleman K, Witlox RS, Walther FJ, Vento M, TePas AB. Variability in the assessment of 'adequate' chest excursion during simulated neonatal resuscitation. Neonatology (2011) 100:99-104. doi:10.1159/000322009

17. van Vonderen JJ, Hooper SB, Kroese JK, Roest AA, Narayen IC, van Zwet EW, et al. Pulse oximetry measures a lower heart rate at birth compared with electrocardiography. J Pediatr (2015) 166:49-53. doi:10.1016/j.jpeds.2014.09.015

18. Schmolzer GM, Kamlin OC, Dawson JA, Te Pas AB, Morley CJ, Davis PG. Respiratory monitoring of neonatal resuscitation. Arch Dis Child Fetal Neonatal Ed (2010) 95:F295-303. doi:10.1136/adc.2009.165878

19. Wyllie J, Bruinenberg J, Roehr CC, Rudiger M, Trevisanuto D, Urlesberger B. European Resuscitation Council Guidelines for resuscitation 2015: section 7. Resuscitation and support of transition of babies at birth. Resuscitation (2015) 95:249-63. doi:10.1016/j.resuscitation.2015.07.029

20. Schilleman K, Witlox RS, van Vonderen JJ, Roegholt E, Walther FJ, Te Pas $\mathrm{AB}$. Auditing documentation on delivery room management using video and physiological recordings. Arch Dis Child Fetal Neonatal Ed (2014) 99:F485-90. doi:10.1136/archdischild-2014-306261

21. Erdelyi MH. The ups and downs of memory. Am Psychol (2010) 65:623-33. doi:10.1037/a0020440

22. Finer NN, Horbar JD, Carpenter JH. Cardiopulmonary resuscitation in the very low birth weight infant: the Vermont Oxford Network experience. Pediatrics (1999) 104:428-34. doi:10.1542/peds.104.3.428

23. Shah PS. Extensive cardiopulmonary resuscitation for VLBW and ELBW infants: a systematic review and meta-analyses. J Perinatol (2009) 29:655-61. doi:10.1038/jp.2009.71

24. DeMauro SB, Roberts RS, Davis P, Alvaro R, Bairam A, Schmidt B. Impact of delivery room resuscitation on outcomes up to 18 months in very low birth weight infants. J Pediatr (2011) 159:546-50. doi:10.1016/j.jpeds.2011.03.025

25. te Pas AB, Davis PG, Hooper SB, Morley CJ. From liquid to air: breathing after birth. J Pediatr (2008) 152:607-11. doi:10.1016/j.jpeds.2007.10.041

26. Vyas H, Milner AD, Hopkins IE. Intrathoracic pressure and volume changes during the spontaneous onset of respiration in babies born by cesarean section and by vaginal delivery. J Pediatr (1981) 99:787-91. doi:10.1016/ S0022-3476(81)80412-X

27. Vyas H, Field D, Milner AD, Hopkin IE. Determinants of the first inspiratory volume and functional residual capacity at birth. Pediatr Pulmonol (1986) 2:189-93. doi:10.1002/ppul.1950020403

28. Higgins RD, Bancalari E, Willinger M, Raju TN. Executive summary of the workshop on oxygen in neonatal therapies: controversies and opportunities for research. Pediatrics (2007) 119:790-6. doi:10.1542/peds.2006-2200

29. Vento M, Saugstad OD. Oxygen supplementation in the delivery room: updated information. J Pediatr (2011) 158:e5-7. doi:10.1016/j.jpeds.2010.11.004

30. Perlman JM, Wyllie J, Kattwinkel J, Atkins DL, Chameides L, Goldsmith JP, et al. Part 11: neonatal resuscitation: 2010 international consensus on cardiopulmonary resuscitation and emergency cardiovascular care science with treatment recommendations. Circulation (2010) 122:S516-38. doi:10.1161/ CIRCULATIONAHA.110.971127

31. Wyllie J, Perlman JM, Kattwinkel J, Atkins DL, Chameides L, Goldsmith JP, et al. Part 11: neonatal resuscitation: 2010 international consensus on cardiopulmonary resuscitation and emergency cardiovascular care science with treatment recommendations. Resuscitation (2010) 81(Suppl 1):e260-87. doi:10.1016/j.resuscitation.2010.08.029

32. Vento M, Moro M, Escrig R, Arruza L, Villar G, Izquierdo I, et al. Preterm resuscitation with low oxygen causes less oxidative stress, inflammation, and chronic lung disease. Pediatrics (2009) 124:e439-49. doi:10.1542/ peds.2009-0434

33. Gluckman PD, Johnston BM. Lesions in the upper lateral pons abolish the hypoxic depression of breathing in unanaesthetized fetal lambs in utero. J Physiol (1987) 382:373-83. doi:10.1113/jphysiol.1987.sp016372

34. Davey MG, Moss TJ, McCrabb GJ, Harding R. Prematurity alters hypoxic and hypercapnic ventilatory responses in developing lambs. Respir Physiol (1996) 105:57-67. doi:10.1016/0034-5687(96)00038-2

35. O'Donnell CP, Kamlin CO, Davis PG, Morley CJ. Crying and breathing by extremely preterm infants immediately after birth. J Pediatr (2010) 156:846-7. doi:10.1016/j.jpeds.2010.01.007

36. Schilleman K, van der Pot CJ, Hooper SB, Lopriore E, Walther FJ, te Pas $A B$. Evaluating manual inflations and breathing during mask ventilation in preterm infants at birth. JPediatr (2013) 162:457-63. doi:10.1016/j. jpeds.2012.09.036

37. Kamlin CO, Dawson JA, O’Donnell CP, Morley CJ, Donath SM, Sekhon J, et al. Accuracy of pulse oximetry measurement of heart rate of newborn infants in the delivery room. J Pediatr (2008) 152:756-60. doi:10.1016/j. jpeds.2008.01.002

38. Schilleman K, Siew ML, Lopriore E, Morley CJ, Walther FJ, Te Pas AB. Auditing resuscitation of preterm infants at birth by recording video and physiological parameters. Resuscitation (2012) 83:1135-9. doi:10.1016/j. resuscitation.2012.01.036

39. McCarthy LK, Morley CJ, Davis PG, Kamlin CO, O'Donnell CP. Timing of interventions in the delivery room: does reality compare with neonatal resuscitation guidelines? J Pediatr (2013) 163:1553-7. doi:10.1016/j. jpeds.2013.06.007

40. Dawson JA, Saraswat A, Simionato L, Thio M, Kamlin CO, Owen LS, et al. Comparison of heart rate and oxygen saturation measurements from Masimo and Nellcor pulse oximeters in newly born term infants. Acta Paediatr (2013) 102:955-60. doi:10.1111/apa.12329

41. Dawson JA, Kamlin CO, Wong C, Te Pas AB, Vento M, Cole TJ, et al. Changes in heart rate in the first minutes after birth. Arch Dis Child Fetal Neonatal Ed (2010) 95:F177-81. doi:10.1136/adc.2009.169102

42. Dawson JA, Kamlin CO, Vento M, Wong C, Cole TJ, Donath SM, et al. Defining the reference range for oxygen saturation for infants after birth. Pediatrics (2010) 125:e1340-7. doi:10.1542/peds.2009-1510

43. Smit M, Dawson JA, Ganzeboom A, Hooper SB, van RJ, Te Pas AB. Pulse oximetry in newborns with delayed cord clamping and immediate skin-toskin contact. Arch Dis Child Fetal Neonatal Ed (2014) 99:F309-14. doi:10.1136/ archdischild-2013-305484

44. Katheria A, Blank D, Rich W, Finer N. Umbilical cord milking improves transition in premature infants at birth. PLoS One (2014) 9:e94085. doi:10.1371/ journal.pone. 0094085

45. Narayen IC, Smit M, van Zwet EW, Dawson JA, Blom NA, Te Pas AB. Low signal quality pulse oximetry measurements in newborn infants are reliable for oxygen saturation but underestimate heart rate. Acta Paediatr (2015) 104:e158-63. doi:10.1111/apa.12932

46. Katheria A, Rich W, Finer N. Electrocardiogram provides a continuous heart rate faster than oximetry during neonatal resuscitation. Pediatrics (2012) 130:e1177-81. doi:10.1542/peds.2012-0784

47. van Vonderen JJ, Roest AA, Siew ML, Blom NA, van Lith JM, Walther FJ, et al. Noninvasive measurements of hemodynamic transition directly after birth. Pediatr Res (2014) 75:448-52. doi:10.1038/pr.2013.241

48. Phillipos E, Solevag AL, Pichler G, Aziz K, van OS S, O’Reilly M, et al. Heart rate assessment immediately after birth. Neonatology (2016) 109:130-8. doi:10.1159/000441940

49. Pichler G, Cheung PY, Aziz K, Urlesberger B, Schmolzer GM. How to monitor the brain during immediate neonatal transition and resuscitation? A systematic qualitative review of the literature. Neonatology (2014) 105:205-10. doi:10.1159/000357162

50. Baik N, Urlesberger B, Schwaberger B, Schmolzer GM, Mileder L, Avian A, et al. Reference ranges for cerebral tissue oxygen saturation index in term neonates during immediate neonatal transition after birth. Neonatology (2015) 108:283-6. doi:10.1159/000438450 
51. Pichler G, Binder C, Avian A, Beckenbach E, Schmolzer GM, Urlesberger B. Reference ranges for regional cerebral tissue oxygen saturation and fractional oxygen extraction in neonates during immediate transition after birth. J Pediatr (2013) 163:1558-63. doi:10.1016/j.jpeds.2013.07.007

52. Schmolzer GM, Kamlin OC, O’Donnell CP, Dawson JA, Morley CJ, Davis PG. Assessment of tidal volume and gas leak during mask ventilation of preterm infants in the delivery room. Arch Dis Child Fetal Neonatal Ed (2010) 95:F393-7. doi:10.1136/adc.2009.174003

53. Kaufman J, Schmolzer GM, Kamlin CO, Davis PG. Mask ventilation of preterm infants in the delivery room. Arch Dis Child Fetal Neonatal Ed (2013) 98:F405-10. doi:10.1136/archdischild-2012-303313

54. Schilleman K, Witlox RS, Lopriore E, Morley CJ, Walther FJ, Te Pas AB. Leak and obstruction with mask ventilation during simulated neonatal resuscitation. Arch Dis Child Fetal Neonatal Ed (2010) 95:F398-402. doi:10.1136/ adc.2009.182162

55. Schmolzer GM, Dawson JA, Kamlin CO, O’Donnell CP, Morley CJ, Davis PG. Airway obstruction and gas leak during mask ventilation of preterm infants in the delivery room. Arch Dis Child Fetal Neonatal Ed (2011) 96:F254-7. doi:10.1136/adc.2010.191171

56. van Vonderen JJ, Hooper SB, Hummler HD, Lopriore E, Te Pas AB. Effects of a sustained inflation in preterm infants at birth. J Pediatr (2014) 165:903-8. doi:10.1016/j.jpeds.2014.06.007

57. Schmolzer GM, Morley CJ, Wong C, Dawson JA, Kamlin CO, Donath SM, et al. Respiratory function monitor guidance of mask ventilation in the delivery room: a feasibility study. J Pediatr (2012) 160:377-81. doi:10.1016/j. jpeds.2011.09.017

58. Bjorklund LJ, Vilstrup CT, Larsson A, Svenningsen NW, Werner O. Changes in lung volume and static expiratory pressure-volume diagram after surfactant rescue treatment of neonates with established respiratory distress syndrome. Am J Respir Crit Care Med (1996) 154:918-23. doi:10.1164/ ajrccm.154.4.8887586

59. Vilstrup CT, Bjorklund LJ, Werner O, Larsson A. Lung volumes and pressure-volume relations of the respiratory system in small ventilated neonates with severe respiratory distress syndrome. Pediatr Res (1996) 39:127-33. doi:10.1203/00006450-199601000-00019

60. Hillman NH, Moss TJ, Kallapur SG, Bachurski C, Pillow JJ, Polglase GR, et al. Brief, large tidal volume ventilation initiates lung injury and a systemic response in fetal sheep. Am J Respir Crit Care Med (2007) 176:575-81. doi:10.1164/rccm.200701-051OC

61. Stenson BJ, Boyle DW, Szyld EG. Initial ventilation strategies during newborn resuscitation. Clin Perinatol (2006) 33:65-82,vi-vii. doi:10.1016/j. clp.2005.11.015

62. Bjorklund LJ, Ingimarsson J, Curstedt T, John J, Robertson B, Werner O, et al. Manual ventilation with a few large breaths at birth compromises the therapeutic effect of subsequent surfactant replacement in immature lambs. Pediatr Res (1997) 42:348-55. doi:10.1203/00006450-199709000-00016

63. Ingimarsson J, Bjorklund LJ, Curstedt $\mathrm{T}$, Gudmundsson S, Larsson A, Robertson B, et al. Incomplete protection by prophylactic surfactant against the adverse effects of large lung inflations at birth in immature lambs. Intensive Care Med (2004) 30:1446-53. doi:10.1007/s00134-004-2227-3

64. Wallace MJ, Probyn ME, Zahra VA, Crossley K, Cole TJ, Davis PG, et al. Early biomarkers and potential mediators of ventilation-induced lung injury in very preterm lambs. Respir Res (2009) 10:19. doi:10.1186/1465-9921-10-19

65. Bach KP, Kuschel CA, Hooper SB, Bertram J, McKnight S, Peachey SE, et al. High bias gas flows increase lung injury in the ventilated preterm lamb. PLoS One (2012) 7:e47044. doi:10.1371/journal.pone.0047044

66. Dawson JA, Schmolzer GM, Kamlin CO, te Pas AB, O'Donnell CP, Donath $\mathrm{SM}$, et al. Oxygenation with T-piece versus self-inflating bag for ventilation of extremely preterm infants at birth: a randomized controlled trial. J Pediatr (2011) 158:912-8. doi:10.1016/j.jpeds.2010.12.003

67. van Vonderen JJ, Hooper SB, Krabbe VB, Siew ML, Te Pas AB. Monitoring tidal volumes in preterm infants at birth: mask versus endotracheal ventilation. Arch Dis Child Fetal Neonatal Ed (2015) 100:F43-6. doi:10.1136/ archdischild-2014-306614

68. Harding R, Hooper SB, Dickson KA. A mechanism leading to reduced lung expansion and lung hypoplasia in fetal sheep during oligohydramnios. Am J Obstet Gynecol (1990) 163:1904-13. doi:10.1016/0002-9378(90)90772-Y

69. Harding R, Hooper SB. Regulation of lung expansion and lung growth before birth. J Appl Physiol (1996) 81:209-24.

70. Mortola JP. Dynamics of breathing in newborn mammals. Physiol Rev (1987) 67:187-243.

71. Siew ML, van Vonderen JJ, Hooper SB, Te Pas AB. Very preterm infants failing CPAP show signs of fatigue immediately after birth. PLoS One (2015) 10:e0129592. doi:10.1371/journal.pone.0129592

72. Te Pas AB, Wong C, Kamlin COF, Dawson JA, Morley CJ, Davis PG. Breathing patterns in preterm and term infants immediately after birth. Pediatr Res (2009) 65:352-6. doi:10.1203/PDR.0b013e318193f117

73. Hooper SB, Fouras A, Siew ML, Wallace MJ, Kitchen MJ, Te Pas AB, et al. Expired $\mathrm{CO}_{2}$ levels indicate degree of lung aeration at birth. PLoS One (2013) 8:e70895. doi:10.1371/journal.pone.0070895

74. van Vonderen JJ, Lista G, Cavigioli F, Hooper SB, Te Pas AB. Effectivity of ventilation by measuring expired $\mathrm{CO}_{2}$ and RIP during stabilisation of preterm infants at birth. Arch Dis Child Fetal Neonatal Ed (2015) 100:F514-8. doi:10.1136/archdischild-2014-307412

75. Peltier LF, Geertsma RH, Youmans RL. Television videotape recording: an adjunct in teaching emergency medical care. Surgery (1969) 66:233-6.

76. Finer NN, Rich W. Neonatal resuscitation: toward improved performance. Resuscitation (2002) 53:47-51. doi:10.1016/S0300-9572(01)00494-4

77. Carbine DN, Finer NN, Knodel E, Rich W. Video recording as a means of evaluating neonatal resuscitation performance. Pediatrics (2000) 106:654-8. doi:10.1542/peds.106.4.654

78. Lindback C, KC A, Wrammert J, Vitrakoti R, Ewald U, Malqvist M. Poor adherence to neonatal resuscitation guidelines exposed; an observational study using camera surveillance at a tertiary hospital in Nepal. BMC Pediatr (2014) 14:233. doi:10.1186/1471-2431-14-233

79. O'Donnell CP, Kamlin CO, Davis PG, Morley CJ. Ethical and legal aspects of video recording neonatal resuscitation. Arch Dis Child Fetal Neonatal Ed (2008) 93:F82-4. doi:10.1136/adc.2007.118505

80. Ellis DG, Lerner EB, Jehle DV, Romano K, Siffring C. A multi-state survey of videotaping practices for major trauma resuscitations. J Emerg Med (1999) 17:597-604. doi:10.1016/S0736-4679(99)00048-7

81. Oakley E, Stocker S, Staubli G, Young S. Using video recording to identify management errors in pediatric trauma resuscitation. Pediatrics (2006) 117:658-64. doi:10.1542/peds.2004-1803

82. Kamlin CO, Schilleman K, Dawson JA, Lopriore E, Donath SM, Schmolzer $\mathrm{GM}$, et al. Mask versus nasal tube for stabilization of preterm infants at birth: a randomized controlled trial. Pediatrics (2013) 132:e381-8. doi:10.1542/ peds.2013-0361

83. Thallinger M, Ersdal HL, Ombay C, Eilevstjonn J, Stordal K. Randomised comparison of two neonatal resuscitation bags in manikin ventilation. Arch Dis Child Fetal Neonatal Ed (2015). doi:10.1136/ archdischild-2015-308754

Conflict of Interest Statement: The authors declare that the research was conducted in the absence of any commercial or financial relationships that could be construed as a potential conflict of interest.

Copyright (c) 2016 van Vonderen, van Zanten, Schilleman, Hooper, Kitchen, Witlox and te Pas. This is an open-access article distributed under the terms of the Creative Commons Attribution License (CC BY). The use, distribution or reproduction in other forums is permitted, provided the original author(s) or licensor are credited and that the original publication in this journal is cited, in accordance with accepted academic practice. No use, distribution or reproduction is permitted which does not comply with these terms. 